\title{
COVID-19 and Higher Education in Agriculture Sector of Developing Countries: Impacts and Prospects
}

\author{
Mubshar Hussain ${ }^{1}$, Sami Ul-Allah ${ }^{2}$, Muhammad Binyameen ${ }^{3}$, Khawar Jabran ${ }^{4}$, Muhammad Farooq ${ }^{5 \star}$,
}

\author{
${ }^{1}$ Department of Agronomy, Bahauddin Zakariya University, Multan, PAKISTAN \\ ${ }^{2}$ College of Agriculture, Bahauddin Zakariya University, Bahadur Sub-campus Layyah, PAKISTAN \\ ${ }^{3}$ Department of Entomology, Bahauddin Zakariya University, Multan, PAKISTAN \\ Nigde Omer Halisdemir University, TURKEY \\ ${ }^{5}$ Department of Plant Sciences, College of Agricultural and Marine Sciences, Sultan Qaboos University, Al-Khoud 123, OMAN \\ `Corresponding Author: farooqcp@squ.edu.om
}

Citation: Hussain, M., Ul-Allah, S., Binyameen, M., Jabran, K., \& Farooq, M. (2022). COVID-19 and Higher Education in Agriculture Sector of Developing Countries: Impacts and Prospects. Pedagogical Research, 7(1), em0111. https://doi.org/10.29333/pr/11440

\begin{tabular}{ll}
\hline ARTICLE INFO & \begin{tabular}{l} 
ABSTRACT \\
\cline { 3 - 4 } Received: 13 Aug. 2021
\end{tabular}$\quad \begin{array}{l}\text { Like all other sectors, higher education in the agriculture sector has been affected by the COVID-19. Both teachers } \\
\text { and students have faced problems in communication, learning and motivation during online education. The major } \\
\text { issues include the limited internet access coupled with poor supply of electricity especially in rural areas, in most } \\
\text { of the developing countries. In this article, we have discussed various challenges faced by agricultural students } \\
\text { and teachers during online teaching and learning after the COVID-19 pandemic. The article also discusses } \\
\text { prospects and strategies to improve online teaching and learning in the higher education of the agriculture sector } \\
\text { of developing countries. }\end{array}$
\end{tabular}

Keywords: agricultural education, learning management system, Moodle, online education

\section{INTRODUCTION}

COVID-19 has emerged as a global crisis and affected almost all walks of life. Education and learning have been greatly disrupted in the era of COVID-19 because of the closure of face-to-face education in universities and schools around the world. Lack of face-to-face learning has particularly affected more the branches of science and education that are of 'applied' nature. An excellent example of it is the "agricultural sciences". In agricultural sciences, the theoretical portion is taught in classrooms and that theoretical part is immediately supplemented by practical in a laboratory or an agriculture field. Unfortunately, this opportunity of teaching a theory and practice of the same topic vanishes in distance learning. Ultimately, neither students can learn a certain agricultural technique, its mechanism and application nor can faculty members achieve the 'course objectives' (learning goals; each course has its certain objectives/goals) in their real essence. This negative impact has been witnessed not only in developing or semi-developed countries such as Pakistan, Turkey, and Oman but also in developed countries including Australia, USA, etc. In a recent assessment on the impact of the COVID-19 epidemic on education, especially in the developing countries, the World Bank reported that most students will have significant challenges in switching to and receiving online education due to a variety of internet access and other barriers (World Bank, 2020).

Practical learning through field and laboratory demonstration is an integral part of agricultural education, therefore this change has greatly affected the communication and learning as well as the evaluation process to evaluate students through practical exams. In addition to the above-mentioned problems, eLearning has also exerted an additional economical pressure mainly on the students and their families to spend money on eLearning devices such as smart mobile phones, tabs and laptops, and internet devices and packages to learn and teach online. This article is aimed at discussing the various impacts of eLearning in higher education of agriculture including challenges and opportunities as well as recommendations for the future in the developing countries.

\section{CHALLENGES}

While eLearning is a golden opportunity for few sectors, there have been several problems in the education sector faced mainly by the students which are summed up in Figure 1 and discussed in the following lines. 


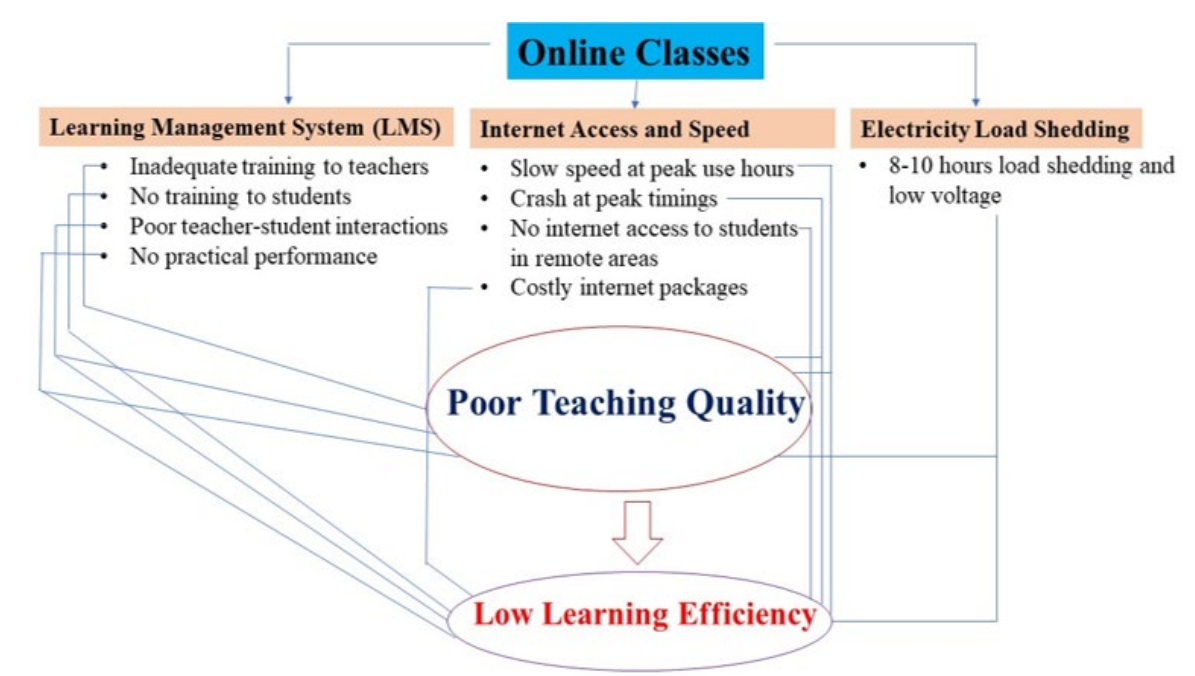

Figure 1. A schematic drawing representing the factors affecting online teaching quality and learning efficiency in agricultural higher education sector during COVID-19

\section{Internet}

Most of the universities in the developing countries have an underdeveloped information technology (IT) infrastructure and, in most cases, the students have only limited access and teachers use these online platforms to provide advisory support or assignments, etc. It must be noted that students in the agricultural HEls belong to both rural and urban areas and even from the remote area where internet facilities are limited due to poor network coverage or in some cases not available at all due to no network coverage. Moreover, the speed of the internet is very slow and not sufficient for online classes. For example, in Pakistan, the Higher Education Commission (HEC) highlighted the issue of the internet being faced by the students and HEC directed all universities in Pakistan to accommodate students from the remote areas in the university hostels, at least during online exams otherwise exams could not be fully successful (Zahra et al., 2020). Major problems of the internet in developing countries include poor connectivity, lack of technical knowledge and financial problem to access the laptop or computer. These internet barriers are not faced only by the rural students from countries like Pakistan, Oman, and Turkey, but also by the students from countries with an advanced infrastructure (Boerngen \& Rickard, 2021; Naik et al., 2021).

\section{Learning Management System}

With the spread of COVID-19, most universities have adopted the learning management system (LMS) as a tool for online teaching and learning. But there was only short or no training at all for the students and teachers about the LMS, which have greatly affected the effectiveness of the system. Moreover, in most of the universities, LMS could not bear the burden of large number of students, and websites often crashed, and the link got down. Therefore, due to limited internet facilities in most of the remote areas, LMS remains only a source for student registration and distribution of study material among the students. This has forced the teachers to use social media tools which even worked at a slower internet speed (Khan, 2021). The teachers were used to share recorded lectures on WhatsApp and did live sessions with the students on Zoom and Google meet for delivering the lectures to the students.

\section{Poor Learning and Teaching}

Adnan and Anwar (2020) surveyed higher education students of different disciplines and reported that although $90 \%$ of the students were qualified to use the computer ( $10 \%$ even could not use computer and internet properly), but $99 \%$ reported that physical learning is necessary for proper understanding and 50\% students voted that effective learning is not possible through online teaching. Due to the lack of internet connection in many of the areas, digital inequities among students and faculty were abruptly exposed. Inadequate prior training for both students and lecturers on the requirements of online learning make the system less efficient (Oyedotun, 2020). Along with learning, teachers also faced problems in online communication similar to the students.

\section{Practical Learning}

Poor network infrastructure, lack of technical knowledge and confidence, uncooperative learning attitude and low attendance during the online lecture remained top of the problems faced by the teachers (Noor et al., 2020). Education is a two-way process i.e., teaching and learning, poor response from any of the side results in ineffective education. With the problems mentioned above, both sides showed limitations. Especially in agriculture, where physical practical education is necessary, the online lecture could not reach the standards of physical education. The problem became critical for the new admission, as they do not have prior knowledge of agriculture and by just online lecture, they even could not understand the basics. On the other hand, surprisingly it was observed that students with poor communication skills interact more frequently with the teacher on social media learning compared to physical learning (Khan, 2021). 


\section{Student Assessments}

The student's assessment and evaluation, due to the unavailability of online evaluation methods, has also been a major issue. If some methods were available, students especially those living in remote areas with limited internet facilities could not use those methods. For theory parts, teachers managed the exams to some extent by taking open book exams within a limited time, but for practical parts, teachers have had to evaluate the students just by the written assignments and exams but no practical performance. Even then, some students from remote areas failed to submit the assignments and written exam sheets within the time limits due to the unavailability of internet access. Another challenge being faced is a poor evaluation of students in the examination due to open book examination coupled with poor internet access. Due to the lack of any monitoring system, many lecturers/tutors have resorted to using multiple-choice questions for the evaluation of the students (Oyedotun, 2020).

\section{Poor Performance Graduates, Less Market Value}

As a result of the online delivery system, many students were compelled to work at home, where they were subjected to numerous distractions and other household concerns (Sutton, 2020); as a result, most students found it difficult to keep concentrated during online learning. These problems of poor learning may result in unemployment for the students of the COVID19 period as they could not compete with the students who have taken physical classes with physical practical work. Therefore, it is a dire need of time to find out the ways to tackle this situation or any other such type of unfortunate conditions in the future. Some students always showed some resistance to the change and do not want to adapt themselves to the online learning environment and therefore need some motivation and special assistance to get them accustomed to LMS and the methods of eLearning.

\section{Economic Hurdles}

Many students, especially in the developing countries where university students sometimes do not have the university fee to pay, are not provided with laptops or laptops of high specifications and a high-quality broadband or internet connection that are the basic requirement of an online class and thus students fail to catch up with their virtual classmates. Another common problem is that most of the students have smartphones but no laptops. It has also been observed that some students have had quite expensive smartphones as that can be used for multipurpose but no laptops and while in a virtual classroom using a small screen makes learning difficult. Moreover, some students live in remote areas where there are no telecom networks or having poor network coverage and thus cannot catch up with the online class learning.

\section{ONLINE LEARNING VS TRADITIONAL LEARNING}

Switching from a traditional classroom and face-to-face instructor training to computer-based learning in the virtual classroom requires a hard struggle, especially for the students who are naive to online technology or digital resources of learning. For example, live lecture and notes taking are common practices in a traditional classroom, but online discussions and better learning require active participation or action, which makes online learning a difficult task for the students. Generally, students have a good knowledge to use new technology and learning tools and thus able to manage computers well, but still, there is a large number of students who cannot fully handle the laptop or other eLearning resources as they have never used it earlier. For example, many students cannot operate basic programs such as Microsoft Word, Excel, and PowerPoint; and therefore are not able to handle their files. Furthermore, many students find fixing basic computer problems troublesome, as they do not know this area. However, technological proficiency is a must for following online courses, as it enables students to manage their assignments and coursework in an organized manner without struggling. A solution to this problem could be knowing exactly what kind of technical support they will need for a certain course as well as properly equipping them with the required learning tools and equipments. Moreover, basic courses in computer literacy enhance students' knowledge in the field; having a fundamental knowledge of computer hardware would help them participate in online classes without interruptions and hindrances. Thus, computer literacy programs may be started for the students from the first class as it has become a basic requirement. This will be helpful for the future generations, and they will have a better understanding to learn through eLearning as compared to the current generation to whom nobody ever taught how to use a touchscreen or navigate a website or have had no experience of using a computer, which is pre-requisite in the eLearning programs.

\section{PROSPECTS AND STRATEGIES}

As a teacher, while teaching online classes on Google meet and Zoom apps, this looks like a good opportunity, especially in terms of preparing quality lectures as compared to classroom lectures. For example, instructors need to put in intensive work and time to design the instruction for the ease of students that they can easily understand the lecture while taking the class online where teachers get no idea what students are receiving as teachers is not watching the whole class due to limited screen. In eLearning, lecture timing can be adjusted according to the ease of students and teachers, which is not possible to have while you have a fixed class schedule and specific time to take a class in a specific lecture room. This elearning's time and place flexibility can attract more and more students to online education. This also has opened an opportunity for educational institutions with limited teachers and space to accommodate students. In addition, it allows the institutions to earn more to meet the budget deficit. 
As agriculture studies are practical oriented, therefore COVID-19 necessitates the paradigm shift in the agricultural education system and revision of curriculum addressing future needs. Students need to equip themselves with technical proficiency to decode the course material. Students need to accept the new learning circumstances with an open mind and heart. A better understanding of the benefits of eLearning and even discussing them with their peers may change this mindset and better prepare students for online classes. Finally, eLearning requires self-motivation, which online learners, especially adults, lacks. Students need to find the motivation to follow the new educational trends and properly equip themselves for future challenges in their education and careers (McKim et al., 2021). Only a positive attitude will help them overcome the challenges in eLearning. Students also need to understand that eLearning could save them a lot of time as they do not have to travel and spend money on traveling as well, so they can use that time and money to practice hard and spend on the digital sources, respectively, to reap the benefits of elearning. Thus, there is also a need to include modern learning techniques (especially online based) for remote teaching. Although IT subjects are included in the agriculture curriculum, these are not sufficient to equip the students for eLearning. The inclusion of more subjects aiming at eLearning may enhance the effectiveness of online education.

Agricultural education is an important and competitive sector, but students do not have prior knowledge of the subject until they are enrolled in it, therefore including this subject in school education may have a positive impact on the students who adopt this subject for higher education.

Training of the teachers for online communication is very important. For online communication, sources other than the internet like television and radio should be adopted. Agriculture universities may develop their FM radio or television channel, where they can record lectures, and time of the lectures may be communicated to the students.

Agriculture graduates must be technically sound to meet the market requirements. Inclusion of private farms for the practical work of students, especially during COVID-19 type epidemics, may make them technically even sounder relative to limited field practical at the university farm. Moreover, at larger private agricultural farms students can maintain social distance in the open air, therefore students can learn without violating the SOPs of government issued for COVID-19. Another alternative to the private farms is to assign home-based practical assignments, which may be included in the curriculum too, to motivate the students even if they are away from the campus.

Last but not least, motivation is the most important aspect in online learning, as students are not physically present and the instructor cannot bind them to listen everything. However, if students are motivated either by the scope of study or the interest in the subject developed by the instructor, students will learn more efficiently. Practical sessions may be arranged on private farms, but for the students, who do not have easy access to the private farms, these can be replaced with some online tutorials in the form of short videos, which students can download easily even with limited internet access.

\section{CONCLUSIONS}

eLearning in agriculture cannot meet the requirements of higher education in a true spirit as practical and fieldwork is a vital part of curricula. Both students and teachers face problems in communication, learning and motivation, especially due to internet problems. Moreover, differential access to high-speed internet also affected learning across rural-urban regions. Social media has emerged as an effective way of communication and learning even with limited internet facilities, but it limits the assessment of students. The introduction of advanced learning management systems like writing board or Moodle may be a better option, but for this purpose internet access may be improved. Courses on elearning methods may be included in the regular curriculum to tackle such types of situations. Thus, there is a need for the overall improvement of online facilities along with the competitiveness of LMS at agricultural HEls. Agriculture universities are required to be better equipped with the technology that they trained capable human resources (Kumar \& Kumar, 2014). Practical sessions cannot be neglected and may be arranged on some private farms, however, as most of the students may not have access to the private farms, therefore these may be replaced with some video tutorials. Rural-urban divide in access to high-speed internet must be reduced and policies should be formed to provide similar internet facilities across the rural-urban regions. Moreover, internet packages to search as well as download the required course material may be given to students at no or negligible cost so that limited economic resources may not become a hurdle in the elearning of students, especially of the developing countries.

Author contributions: All authors have sufficiently contributed to the study, and agreed with the results and conclusions.

Funding: No funding source is reported for this study.

Declaration of interest: No conflict of interest is declared by authors.

\section{REFERENCES}

Adnan, M., \& Anwar, K. (2020). Online learning amid the COVID-19 pandemic: Students' perspectives. Journal of Pedagogical Sociology and Psychology, 2(1), 45-51. https://doi.org/10.33902/JPSP.2020261309

Boerngen, M. A., \& Rickard, J. W. (2021). To zoom or not to zoom: The impact of rural broadband on online learning. Natural Sciences Education 50(1). https://doi.org/10.1002/nse2.20044

Khan, T. M. (2021). Use of social media and WhatsApp to conduct teaching activities during the COVID-19 lockdown in Pakistan. International Journal of Pharmacy Practice, 29(1), 90-90. https://doi.org/10.1111/ijpp.12659 
Kumar, A., \& Kumar, V. A. (2014). Pedagogy in higher education of agriculture. Procedia-Social and Behavioral Sciences 152, 89-93. https://doi.org/10.1016/j.sbspro.2014.09.160

McKim, A. J., Sorensen, T. J., \& Burrows, M. (2021). The COVID-19 pandemic and agricultural education: An exploration of challenges faced by teachers. Natural Sciences Education, 50(1). https://doi.org/10.1002/nse2.20060

Naik, G. L., Deshpande, M., Shivananda, D. C., Ajey, C. P., \& Patel, G. C. M. (2021). Online teaching and learning of higher education in India during COVID-19 emergency lockdown. Pedagogical Research, 6(1), em0090. https://doi.org/10.29333/pr/9665

Noor, S., Isa, F. M., \& Mazhar, F. F. (2020). Online teaching practices during the COVID-19 pandemic. Educational Process: International Journal 9(3), 169-184. https://doi.org/10.22521/edupij.2020.93.4

Oyedotun, T. D. (2020). Sudden change of pedagogy in education driven by COVID-19: Perspectives and evaluation from a developing country. Research in Globalization, 2, 100029. https://doi.org/10.1016/j.resglo.2020.100029

Sutton, H. (2020). Keep your mission student-centered, even in the face of crisis. Dean \& Provost, 21(10), 12-12. https://doi.org/10.1002/dap.30738

World Bank (2020). Remote learning and COVID-19: The use of educational technologies at scale across an education system as a result of massive school closings in response to the COVID-19 pandemic to enable distance education and online learning. Versão de, 16.

Zahra, F., Gul, A., Iqbal, A., Ghafoor, T., \& Ambreen, A. (2020). The Impact of COVID-19 on rural areas students of Pakistan: Moderating role of HEC policy and internet service. Asian Journal of Contemporary Education 4(2), 69-79. https://doi.org/10.18488/journal.137.2020.42.69.79 